Adenoid cystic carcinoma (AdCC) is a common tumour of the minor salivary gland, rarely seen in other anatomical locations. In particular, AdCC of the breast accounts for $<0.1 \%$ of patients diagnosed with breast cancer. Here we report our institutional experience with three cases of breast AdCC diagnosed between 2009 and 2017.

Mean age of women included in the report was 53 (range from 41 to 62). One case was of no special subtype, two were solid variants and one presented with a component of invasive ductal carcinoma. At diagnosis in all cases neither lymph node involvement nor distal metastases were detected. All patients underwent surgical resection of the tumour - mastectomy or lumpectomy, followed by either adjuvant radiotherapy and chemotherapy (one case), chemotherapy without radiotherapy (one case) or no treatment (one case). Two patients were reported to develop metastatic disease. No deaths were recorded.

In contrast to other anatomical locations AdCC of the breast is regarded as a rare tumour with low malignant potential. However, as shown in our case series, it can present as an aggressive disease with distal metastases, which calls for deep awareness among both pathologists and clinicians involved in the process of diagnosis and therapy.

Key words: adenoid cystic carcinoma, breast cancer, histopathology.

Contemp Oncol (Pozn) 2020; 24 (4): 263-265 DOI: https://doi.org/10.5114/wo.2020.99025

\section{Adenoid cystic carcinoma of the breast - an uncommon malignancy with unpredictable clinical behaviour. A case series of three patients}

Julia M. Sołek, Marcin Braun, Marta Kalwas, Dorota Jesionek-Kupnicka, Hanna M. Romańska

Department of Pathology, Chair of Oncology, Medical University of Lodz, Lodz, Poland

\section{Introduction}

Adenoid cystic carcinoma (AdCC) of the breast, first described by Billroth in 1856 [1], is histologically similar to its counterpart in the salivary gland, but it usually has an indolent course, good prognosis, and is very rare (comprising $<0.1 \%$ of all primary breast carcinomas) [1, 2]. AdCC affects mainly Caucasian women of age ranging from 33 to 97 years (mean age of 64) [3]. About $50 \%$ of tumours are found in a periareolar region and are wellcircumscribed, palpable, tender masses, often associated with pain and nipple retraction [4]. It is typically a slow-growing lesion without the involvement of locoregional lymph nodes (in less than $2 \%$ of cases) or presence of distant metastases [4]. Diagnosis is based on the histopathological presentation. The essential criteria include: an invasive carcinoma with neoplastic epithelial and myoepithelial cells, glandular lumina filled with epithelial mucins and pseudolumina filled with stromal matrix, basal lamina and fibroblasts (WHO $5^{\text {th }}$ ed) [5]. There are three variants of architectural arrangement: tubular, cribriform and solid, the latter being associated with the worst prognosis [1]. The profile of most AdCC cases is consistent with that of triple negative breast cancer (TNBC; ER/PR/HER2-negative), but in contrast to TNBC, AdCC is characterized by an excellent prognosis (5-, 10-, and 15-year survival rates are $98.1 \%, 94.9 \%$, and $91.4 \%$, respectively) [6]. Since most of the cases behave indolently, conserving therapy is the recommended management. However, AdCC of the breast can pursue an aggressive course manifesting in locoregional recurrences and metastatic spread [3]. The reported frequency of aggressive breast AdCC varies from $1 \%$ to $20 \%$ of all reported cases [2]. As the potential for aggressiveness is still poorly characterized, conserving therapy is routinely applied, which understandably being ineffectual in some cases, allows the disease to progress. Therefore, there is an urgent need to fill the gap in our knowledge about molecular and clinical aspects of breast AdCC to assist selection of patients for appropriate and efficient therapies.

Here, we report our institutional experience with three breast AdCC diagnosed in the period of 8 years from 2009 to 2017.

\section{Case report}

Mean age of women $(n=3)$ included in the report was 53 (ranged from 41 to 62). All patients presented localized disease, which manifested as palpable masses detected on physical examination. Fine-needle aspiration (FNA) was performed in each case in order to verify a suspicion of malignant nature of lesions. In all cases aspirated cytological smears were highly cellular and contained cells with bland nuclear features and mucoid globules 
(Fig. 1A). On the basis of these cytological findings resection of the tumours was recommended. Histopathological analysis of all surgical specimens showed a dual cell population of epithelial and myoepithelial cells lining true glandular spaces and pseudolumina, respectively. In two cases cells were arranged in a solid growth pattern. In one of these AdCC presented with a component of invasive ductal carcinoma (IDC). At diagnosis there were no cases with either nodal involvement or distal metastases. Oestrogen receptors (ER), progesterone receptor (PR) and human epidermal growth factor receptor 2 (HER2), assessed immunohistochemically, were negative in all cases (Fig. 1B). Immunohistochemistry (IHC) for epithelial (CD117) and myoepithelial markers (calponin, CK4/5, p63, SMA) showed a characteristic organization around true glandular spaces and pseudolumina (Fig. 1C-1F). These morphological and phenotypic (IHC) features were consistent with breast AdCC and ruled out collagenous spherulosis and cribriform carcinoma - the main conditions considered in the differential diagnosis.

The first patient was diagnosed with solid AdCC. Initially she underwent surgical resection of the tumour and received adjuvant radiotherapy. However, after 21 months the patient developed distant metastases in the brain, lung and liver and palliative chemotherapy was applied (4 cycles of AC - doxorubicin and cyclophosphamide). The second patient was diagnosed with solid AdCC with a co-existing IDC component. The disease progressed on the computed tomography, which detected lung metastases one month after the initial diagnosis. The patient underwent surgical resection followed by adjuvant radiotherapy and chemotherapy with four different regimens: AC (doxorubicin and cyclophosphamide), Taxotere (docetaxel), Xeloda (capecitabine) and cisplatin in monotherapy. Despite chemotherapy treatment being applied in both patients the metastatic changes did not significantly regress. In the last patient the subtype of AdCC was not specified at the time of diagnosis, but after re-evaluation it was subtyped as classic AdCC. The patient underwent surgical resection and neither progression into metastatic disease nor recurrences during 11 months of the follow-up were recorded. No patient has died during follow-up. Information about the patients is summarized in Table 1.

\section{Discussion}

AdCC is a rare neoplasm, which can occur in many different body sites. The most common location is the salivary gland, where it is the most frequently detected malignancy of latent, but aggressive behaviour. Outside the salivary gland AdCC is rarely detected [2]. As existing data on evaluation of prognostic and predictive features of the offsite tumours are limited, the improvement of management of AdCC patients requires widely available, shared clinical experience. Here we report a small case series of AdCC of the breast, depicting its atypical clinical course.

The WHO Classification of Tumours of the Breast 2019 indicates that the histological subtype of breast AdCC should be considered as a prognostic indicator. It is suggested that only the classic adenoid cystic carcinoma (classic AdCC) with cribriform and tubular differentiation shows favourable behaviour and can be treated with
A
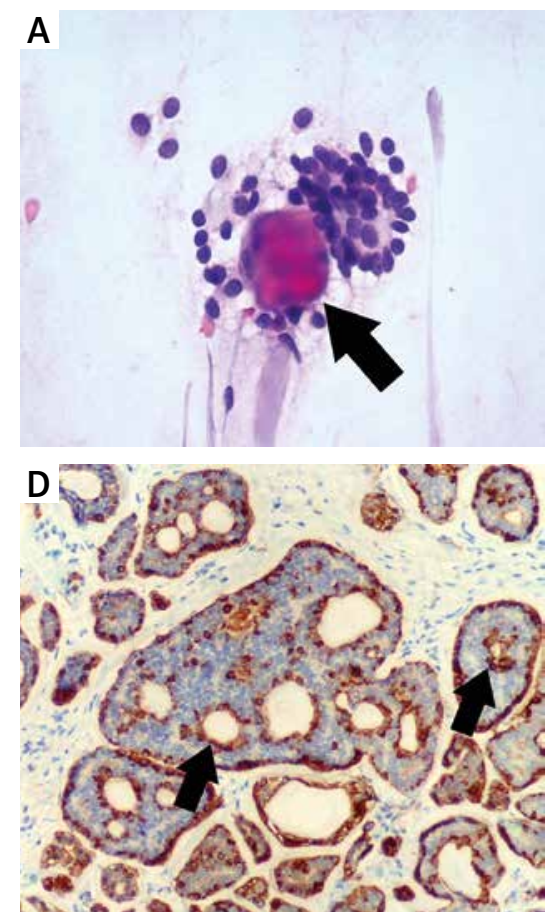
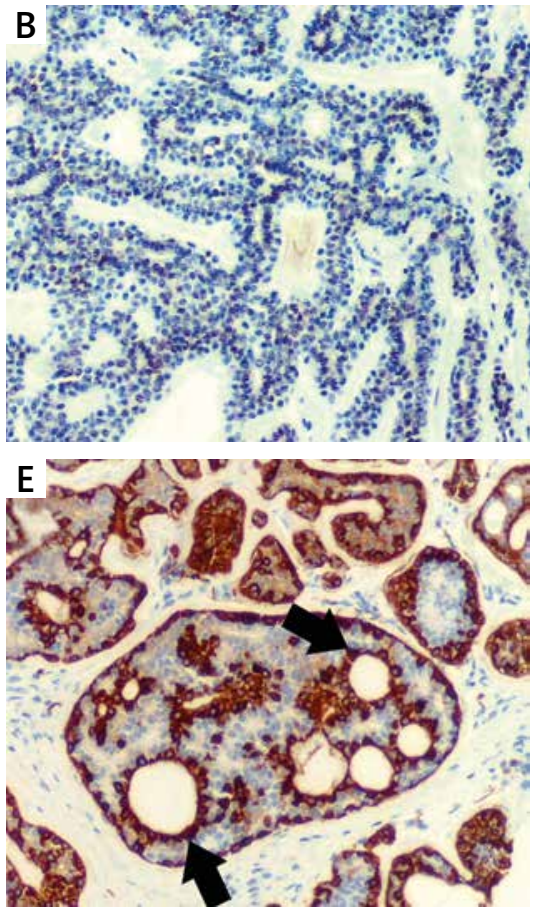

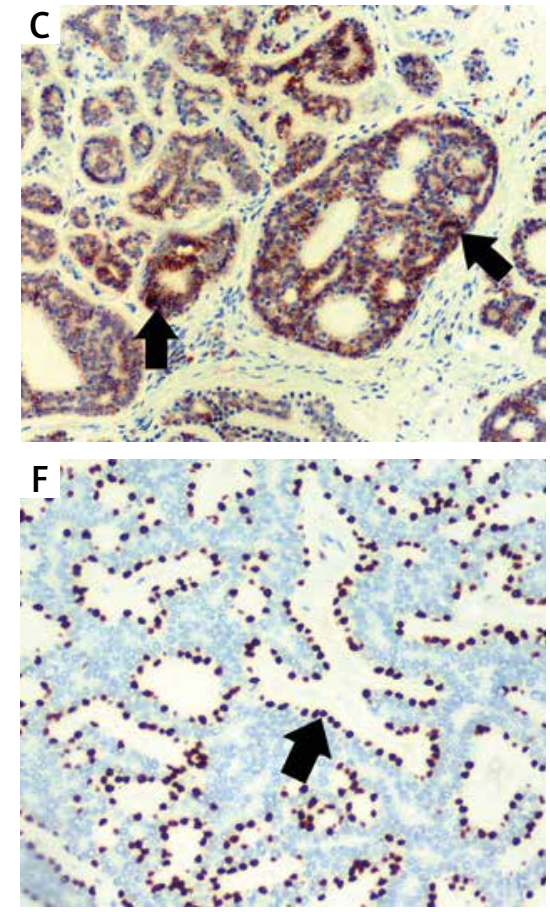

Fig. 1. A) Cytological image H\&E, a black arrow shows hyaline globule surrounded by cells with bland nuclear feature. B) Immunohistochemical staining showing ER, PR and HER2 negativity. C) Immunohistochemistry for CD117 showing positive cells around true glandular spaces - black arrows, and negative cells around pseudolumina. D) Immunohistochemistry for calponin showing positive cells around pseudolumina - black arrows and negative cells around true glandular spaces. E) Immunohistochemistry for SMA showing positive cells around pseudolumina - black arrows, and negative cells around true glandular spaces. F) Immunohistochemistry for p63 showing positive cells around pseudolumina - black arrow and negative cells around true glandular spaces 
Table 1. Patients' characteristics

\begin{tabular}{|c|c|c|c|c|c|c|}
\hline Age & $\begin{array}{l}\text { Stage } \\
\text { at presentation }\end{array}$ & Histological subtype & $\begin{array}{l}\text { Follow-up } \\
\text { (months) }\end{array}$ & Metastasis & Treatment & $\begin{array}{l}\text { Treatment } \\
\text { response }\end{array}$ \\
\hline 52 & $\| A(T 2 N O M x)$ & $\begin{array}{c}\text { SB-AdCC/AdCC with high-grade } \\
\text { transformation }\end{array}$ & $\begin{array}{l}\text { DFS }=1 \\
O S=16\end{array}$ & Lungs & $\begin{array}{c}\text { Mastectomy + radiotherapy + } \\
\text { chemotherapy according to } \\
4 \text { different chemotherapy schedules }\end{array}$ & SD \\
\hline 41 & IA (T1NOMx) & $\begin{array}{l}\text { SB-AdCC/AdCC with high-grade } \\
\text { transformation and accompanying } \\
\text { invasive ductal carcinoma G3 }\end{array}$ & $\begin{array}{l}\mathrm{DFS}=23 \\
\mathrm{OS}=25\end{array}$ & $\begin{array}{l}\text { Brain, } \\
\text { lungs, } \\
\text { liver }\end{array}$ & $\begin{array}{l}\text { Tumourectomy + adjuvant } \\
\text { radiotherapy + } 4 \text { cycles } \\
\text { of chemotherapy }\end{array}$ & SD \\
\hline 62 & IA (T1NOMx) & Classic AdCC & $\begin{array}{l}\mathrm{DFS}=11 \\
\mathrm{OS}=11\end{array}$ & No & Mastectomy & $C R$ \\
\hline
\end{tabular}

AdCC with high-grade transformation - adenoid cystic carcinoma with high-grade transformation

radical surgery alone. Two other subtypes, i.e. solid-basaloid adenoid cystic carcinoma (SB-AdCC) and adenoid cystic carcinoma with high-grade transformation (AdCC with high-grade transformation), have high probability to develop local recurrences and distal metastases, but the data on available treatment are very limited [5]. Our report includes cases diagnosed before the new WHO Classification was published. Adopting the new criteria, the case with no local recurrences or distant metastases would be reclassified as the classic AdCC subtype, and those that presented an aggressive course would belong to the two other categories. The indolent nature of classic AdCC is thought to be due to genetic stability. On the other hand, the malignant potential of SB-AdCC and AdCC with high-grade transformation has been associated with MYB-NFIB gene fusion [1, 2].

Most of the currently available therapy recommendations consider breast AdCC as indolent lesions and thus are limited to local treatment. However, there is growing evidence, including our report, that a malignant transformation is probable [3]. Miyai et al. reported recurrences in seven out of nineteen cases, two of which progressed to metastatic disease leading to patient death [2]. Importantly, only one of these patients received adjuvant radiotherapy while the others underwent surgical treatment alone. This suggests that the commonly adopted therapeutic approach overlooks the potential for malignant transformation of breast AdCC. Recommendations for systemic treatment are limited and mostly based on the treatment applied to AdCC of the salivary gland [2]. In our report two of the patients diagnosed with SB-AdCC and AdCC with high-grade transformation subtypes received therapy based on surgery and adjuvant radiotherapy and chemotherapy. In contrast, one patient who was diagnosed with classic AdCC received only surgical resection without any adjuvant therapy.

This suggests that according to the new WHO classification only the classic subtype of breast AdCC should be treated as indolent. The fact that the malignant potential of AdCC might be underestimated indicates a high need for adjustment of current treatment recommendations of breast AdCC to include primarily its histological subtype.

\section{Conclusions}

Despite being commonly reported as indolent tumours, the breast AdCC can present as an aggressive malignancy with distant metastases. The new WHO classification emphasizes the prognostic value of histological subtypes, which provides valuable information about the aggressive potential of AdCC of the breast. Precise recognition consistent with the current WHO Classification including histological subtype gives clinicians an important clue about the clinical course and should guide effective clinical decision-making in the management of patients with breast AdCC.

\section{The authors declare no conflict of interest.}

\section{References}

1. Senger JL, Kanthan R. Adenoid Cystic Carcinoma of the Breast A Focused Review. JSM Surg Oncol Res Rev 2016; 1: 1008.

2. Miyai K, Schwartz MR, Divatia MK, Anton RC, Park YW, Ayala AG, Ro JY. Adenoid cystic carcinoma of breast: Recent advances. World J Clin Cases 2014; 2: 732-741.

3. Mhamdi HA, Kourie HR, Jungels C, Aftimos P, Belbaraka R, Piccart-Gebhart M. Adenoid cystic carcinoma of the breast - an aggressive presentation with pulmonary, kidney, and brain metastases: a case report. J Med Case Rep 2017; 11: 303.

4. Chen QX, Li JJ, Wang XX, Lin PY, Zhang J, Song CG, Shao ZM. Similar outcomes between adenoid cystic carcinoma of the breast and invasive ductal carcinoma : a population-based study from the SEER 18 database. Oncotarget 2016; 8: 6206-6215.

5. WHO Classification of Tumours Editorial Board. WHO Classification of Tumours of the Breast, $5^{\text {th }}$ ed. IARC Press, Lyon 2019.

6. Ghabach B, Anderson WF, Curtis RE, Huycke MM, Lavigne JA, Dores GM. Adenoid cystic carcinoma of the breast in the United States (1977 to 2006): a population-based cohort study. Breast Cancer Res 2010; 12: R54.

\section{Address for correspondence}

\section{Marcin Braun}

Department of Pathology

Chair of Oncology

Medical University of Lodz

251 Pomorska St.

92-213 Lodz, Poland

e-mail: braunmarcin@gmail.com

Submitted: 14.07 .2020

Accepted: 9.08 .2020 